\title{
Glutamate Uptake Limits Synaptic Excitation of Retinal Ganglion Cells
}

\author{
Matthew H. Higgs and Peter D. Lukasiewicz \\ Department of Ophthalmology and Visual Sciences and Neuroscience Program, Washington University School of \\ Medicine, St. Louis, Missouri 63110-1093
}

\begin{abstract}
EPSCs of retinal ganglion cells decay more slowly than do those of most other CNS neurons, in part because of the long time course of glutamate release from bipolar cells. Here we investigated how glutamate clearance and AMPA receptor desensitization affect ganglion cell EPSCs in the salamander retinal slice preparation. Inhibition of glutamate uptake greatly prolonged ganglion cell EPSCs evoked by light or monosynaptic electrical stimuli but had little effect on spontaneous miniature EPSCs (mEPSCs). This suggests that single quanta of glutamate are cleared rapidly by diffusion but multiple quanta can interact to lengthen the postsynaptic response. Some interaction between quanta is likely to occur even when glutamate uptake is not inhibited. This seems to depend on quantal content, because reducing glutamate release with low $\mathrm{Ca}^{2+}$,
\end{abstract}

Retinal ganglion cell light responses represent the final outcome of retinal processing. In salamander, most ganglion cells are ON-OFF cells that respond transiently at light onset and offset (Mittman et al., 1990). The ability of these cells to respond to high-frequency changes in illumination may be limited by the kinetics of their excitatory and inhibitory synaptic input. Thus, it is important to understand the factors that shape ganglion cell synaptic currents.

The kinetics of synaptic currents are determined by the time course of transmitter release, the rate of transmitter clearance, and the kinetics of postsynaptic receptors. Retinal bipolar cells undergo graded depolarization and can release glutamate in a prolonged manner (Tachibana and Okada, 1991; von Gersdorff and Matthews, 1994; Lagnado et al., 1996; Matsui et al., 1998). The time course of glutamate at postsynaptic receptors may be further lengthened if clearance is slow. Glutamate is removed from the synapse by diffusion and possibly by uptake. It has been shown that diff usion is sufficient to clear a quantum of transmitter rapidly from a synaptic cleft (Eccles and Jaeger, 1958; Clements et al., 1992; Vandenbranden et al., 1996). However, when many quanta are released from closely spaced sites, rapid diffusive equilibration may leave significant residual transmitter, which is cleared much more slowly (Isaacson et al., 1993; Rossi et al., 1995;

Received Nov. 20, 1998; revised Feb. 24, 1999; accepted March 2, 1999.

This work was supported by National Institutes of Health Grants EY08922 (P.D.L.), GM08151 (M.H.H.), and EY02687 (a core grant to the Department of Ophthalmology) and by Research to Prevent Blindness. We thank Drs. James Heuttner, Carl Romano, and Steven Mennerick for critical reading of this manuscript and Drs. Charles Zorumski and Robert Wilkinson for helpful discussions.

Correspondence should be addressed to Dr. Peter D. Lukasiewicz, Department of Ophthalmology and Visual Sciences, Campus Box 8096, Washington University School of Medicine, St. Louis, MO 63110-1093.

Copyright (C) 1999 Society for Neuroscience $0270-6474 / 99 / 193691-10 \$ 05.00 / 0$ paired-pulse depression, or weak stimuli shortened the EPSC decay. High quantal content glutamate release may lead to desensitization of postsynaptic receptors. We reduced the extent of AMPA receptor desensitization by holding ganglion cells at positive potentials. This increased the amplitude of the late phase of evoked EPSCs but did not affect the decay rate after the first $50 \mathrm{msec}$ of the response. In contrast, the holding potential had little effect on mEPSC kinetics. Our results suggest that desensitization limits the late phase of AMPA receptor-mediated EPSCs, whereas glutamate uptake controls the duration of both AMPA and NMDA receptor-mediated responses.

Key words: glutamate transporter; retina; ganglion cell; AMPA receptor; miniature EPSC; glutamate receptor desensitization
Otis et al., 1996; Kinney et al., 1997). Uptake can be important for removal of this residual transmitter, whereas receptor desensitization may limit the late phase of the postsynaptic response.

In the salamander retinal slice, it was estimated that $\sim 200$ quanta of glutamate are released onto the dendrites of each ON-OFF ganglion cell during a transient light response (Taylor et al., 1995). Because light stimuli elicit glutamate release onto many neighboring amacrine and ganglion cells, whose dendrites overlap in the inner plexiform layer (IPL), a larger number of quanta may be released within nearby regions of extracellular space. The extent to which residual glutamate accumulates will depend on the efficiency of clearance. Several subtypes of glutamate transporters have been found in the IPL of vertebrate retinas (Rauen et al., 1996; Schultz and Stell, 1996; Lehre et al., 1997; Eliasof et al., 1998), but the effect of glutamate uptake on inner retinal synaptic transmission has not been investigated.

We report here that inhibition of glutamate uptake greatly prolonged ganglion cell EPSCs in the salamander retinal slice. In contrast, reducing AMPA receptor desensitization by holding the cell at a positive potential increased the amplitude of the late phase of the EPSC but did not affect its rate of decay. Our results suggest that desensitization and glutamate uptake both shape ganglion cell responses.

\section{MATERIALS AND METHODS}

Retinal slices. Slices $(150 \mu \mathrm{m})$ were prepared from larval tiger salamander eyes as described by Lukasiewicz et al. (1994). Tiger salamanders were obtained from Charles Sullivan (Nashville, TN) and housed in aquaria at $5^{\circ} \mathrm{C}$ on a $12: 12 \mathrm{hr}$ light/dark cycle.

Solutions and drugs. The pipette solution for ganglion cell recordings contained (in $\mathrm{mm}$ ): 71 cesium gluconate, 8 tetraethylammonium chloride, $0.4 \mathrm{MgCl}_{2}, 10 \mathrm{Cs}_{4}$ BAPTA, and $10 \mathrm{Na}$-HEPES, adjusted to $\mathrm{pH} 7.5$ with $\mathrm{HCl}$. The pipette solution for bipolar cell voltage recordings contained (in $\mathrm{mm}$ ): 86.1 potassium gluconate, $7.5 \mathrm{KCl}, 3.4 \mathrm{NaCl}, 0.2 \mathrm{EGTA}, 10$ 


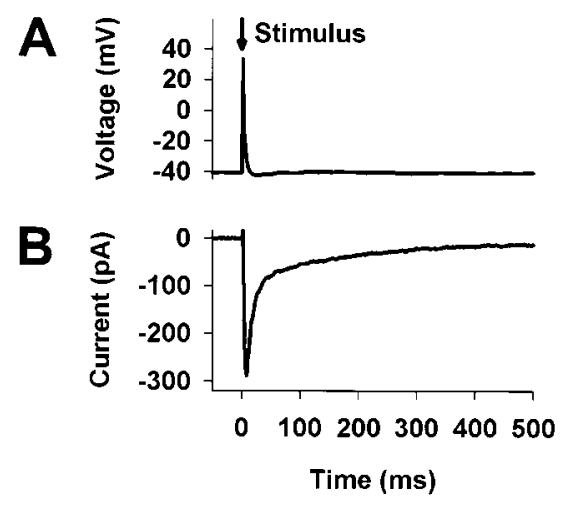

Figure 1. Electrical stimulation in the OPL depolarizes bipolar cells briefly and evokes AMPA receptor-mediated ganglion cell EPSCs with fast and slow components. $A$, Voltage response of an ON bipolar cell to a $5 \mu \mathrm{A}, 1 \mathrm{msec}$ positive current pulse delivered to the OPL $\sim 20 \mu \mathrm{m}$ lateral to the soma. $B$, AMPA receptor-mediated ganglion cell EPSC evoked by a similar $5 \mu \mathrm{A}, 1 \mathrm{msec}$ stimulus.

Na-HEPES, $5 \mathrm{Mg}_{1.5} \mathrm{ATP}$, and $0.5 \mathrm{Na}_{3} \mathrm{GTP}$, adjusted to $\mathrm{pH} 7.5$ with $\mathrm{KOH}$. Lucifer yellow $(0.02 \%)$ was added to both solutions to allow visualization of cell processes by fluorescence epi-illumination. The bath solution contained (in $\mathrm{mM}$ ): $112 \mathrm{NaCl}, 2 \mathrm{KCl}, 2 \mathrm{CaCl}_{2}, 1 \mathrm{MgCl}_{2}, 5$ glucose, and 5 HEPES, adjusted to $\mathrm{pH} 7.8$ with $\mathrm{NaOH}$. Membrane potentials were corrected for junction potentials $(-10 \mathrm{mV}$ for the ganglion cell solution; $-15 \mathrm{mV}$ for the bipolar cell solution). During all experiments, glycine receptors were blocked with strychnine $(10 \mu \mathrm{M})$, and $\mathrm{GABA}_{\mathrm{A}}$ and $\mathrm{GABA}_{\mathrm{C}}$ receptors were blocked with picrotoxin (150 $\mu \mathrm{M})$. For recording of AMPA receptor-mediated EPSCs, NMDA receptors were blocked with D-2-amino-5-phosphonopentanoic acid (D-AP-5; $50 \mu \mathrm{M})$. In experiments at positive holding potentials, MK-801 $(2 \mu \mathrm{M})$ was added to block any remaining NMDA receptor-mediated currents. For NMDA receptor-mediated EPSCs, AMPA and kainate receptors were blocked with 2,3-dihydroxy-6-nitro-7-sulfamoylbenzo(f)quinoxaline (NBQX; $5 \mu \mathrm{M}$ ), and metabotropic glutamate receptor 6 (mGluR6) on the dendrites of ON bipolar cells was continuously activated with L-(+)-2amino-4-phosphonobutyric acid (L-AP-4; $1 \mu \mathrm{M}$ ). A large area of the slice was superfused with control and drug solutions through a large-diameter pipette connected to a gravity perfusion system. Unless otherwise indicated, all chemicals were obtained from Sigma (St. Louis, MO). L-AP-4, D-AP-5, and NBQX were obtained from Precision Biochemicals (Vancouver, British Columbia, Canada); L-trans-pyrrolidine-2,4-dicarboxylic acid (PDC) was obtained from Tocris (Ballwin, MO).

Light stimulation. The light stimulation apparatus and procedures were as described previously (Lukasiewicz and Roeder, 1995; Lukasiewicz et al., 1995). However, the retinal slices were prepared and viewed under dim white light and thus were not dark-adapted. The light source for stimulation was a tungsten-halogen lamp (20 W; Ealing Electro-Optics, Holliston, MA). Full-field white light stimuli were used. The intensity of the unattenuated light stimulus was equivalent to $3.6 \times 10^{16}$ quanta $\cdot \mathrm{cm}^{-2} \cdot \mathrm{sec}^{-1}$ of a monochromatic light of $500 \mathrm{~nm}$. This was attenuated by $2.5-4 \log$ units using neutral density filters.

Electrical stimulation. For direct stimulation of multiple bipolar cells, positive current pulses $(1 \mathrm{msec} ; 1-10 \mu \mathrm{A})$ were applied to the outer plexiform layer (OPL) through a Ringer's solution-filled pipette as described by Cook et al. (1998). The pulses were generated by a constantcurrent stimulator (Grass S48 with stimulus isolation unit PSIU6, West Warwick, RI). The pipettes used were identical to those used for recording and were inserted just into the OPL directly above the ganglion cell that was being recorded. Figure $1 A$ shows a bipolar cell voltage response evoked by a $5 \mu \mathrm{A}, 1 \mathrm{msec}$ stimulus. On average, bipolar cells near the stimulating electrode were depolarized from a resting potential of $-47 \pm$ 2 to $+30 \pm 18 \mathrm{mV}(n=8)$. The voltage response peaked $1.7 \pm 0.1 \mathrm{msec}$ after the stimulus onset and decayed with an exponential time constant of $3.6 \pm 0.5 \mathrm{msec}$. The bipolar cell voltage responses were depolarizing in ON bipolar cells as well as in OFF bipolar cells, and they reversed polarity when a negative current pulse was applied. Thus, the bipolar cell responses seem to result directly from the electrical stimulus rather than from evoked transmitter release in the OPL. Figure $1 B$ shows an AMPA receptor-mediated ganglion cell EPSC evoked by a $5 \mu \mathrm{A}, 1 \mathrm{msec}$ stim- ulus. The amplitude of EPSCs evoked by this method was much larger than that of newt ganglion cell EPSCs evoked by depolarization of single bipolar cells (Matsui et al., 1998), indicating that multiple bipolar cells provide synaptic input to each ganglion cell.

Recording. The microscope system and patch-clamp apparatus used were described by Lukasiewicz and Roeder (1995). Electrodes were pulled from borosilicate glass (TW150F-4; WPI, Sarasota, FL) with a Sachs-Flaming puller (Sutter Instruments, Novato, CA) and had measured resistances of $\sim 5 \mathrm{M} \Omega$. The measured series resistances were typically $20 \mathrm{M} \Omega$. Data were digitized and stored with a 486 personal computer using a Labmaster DMA data acquisition board (Scientific Solutions, Solon, OH). For evoked EPSC recordings, Patchit software (White Perch Software, Somerville, MA) was used to generate voltage command outputs, acquire data, trigger the stimulator or shutter, and control the drug perfusion system. Evoked EPSC data were filtered at 1 $\mathrm{kHz}$ with the four-pole Bessel low-pass filter on the Axopatch 200B and were sampled at $0.5-2 \mathrm{kHz}$. For spontaneous EPSC recordings, Fetchex data acquisition software (Axon Instruments, Foster City, CA) was used to generate voltage command outputs and acquire data. Spontaneous EPSC data were filtered at $2 \mathrm{kHz}$ and sampled at $5 \mathrm{kHz}$.

Analysis. For evoked EPSCs, Tack software (White Perch Software) was used to average records and determine the peak current and time to peak (from stimulus onset). The decay of some EPSCs was poorly described by any number of exponentials, because of a hump after a fast component. Thus, the decay time $\left(D_{37}\right)$ was measured from the peak to $37 \%$ of peak current using Sigma Plot software (SPSS, Chicago, IL). Spontaneous miniature EPSCs (mEPSCs) were analyzed using MiniAnalysis software (Jaejin Software, Leonia, NJ). Each event was inspected, and spurious noise peaks and overlapping events were rejected. The amplitude, time from onset to peak, and $D_{37}$ of each individual event were determined, and the mean value of each measure was calculated for each cell. Data reported are averages of these mean values across multiple cells. mEPSC traces shown are averages of 33-374 events aligned by the event onset. All results are expressed as the mean value \pm 1 SEM. Levels of statistical significance were determined using paired Student's $t$ tests.

\section{RESULTS}

\section{Inhibition of glutamate uptake prolongs ganglion cell EPSCs}

We determined the effect of glutamate uptake on light-evoked, AMPA receptor-mediated ganglion cell EPSCs by applying the competitive uptake inhibitor PDC $(300 \mu \mathrm{M})$. This drug has been shown to block all known subtypes of sodium-dependent glutamate transporters (Arriza et al., 1994; Eliasof et al., 1998). For these experiments, light-adapted retinal slices were stimulated with full-field white light for 5-10 sec. GABA, glycine, and NMDA receptors were blocked with picrotoxin $(150 \mu \mathrm{M})$, strychnine $(10 \mu \mathrm{M})$, and D-AP-5 $(50 \mu \mathrm{M})$, respectively. Figure $2 A$ shows the effect of PDC on light-evoked EPSCs recorded from an $\mathrm{ON}-\mathrm{OFF}$ ganglion cell at a holding potential of $-75 \mathrm{mV}$. In seven ON-OFF ganglion cells, PDC significantly increased the peak amplitude (Fig. $2 B$ ) and decay time (Fig. $2 D$ ) of both ON and OFF responses. In most cells, PDC also lengthened the time from light onset to the peak of the ON response, but this effect was not significant (Fig. 2C). The simplest explanation for the prolongation of both ON and OFF responses is that PDC slows clearance of glutamate from bipolar cell-ganglion cell synapses in the IPL. However, inhibition of glutamate clearance from photoreceptor-bipolar cell synapses in the OPL is also likely to affect the ganglion cell light response.

To determine more directly whether glutamate uptake can affect synaptic transmission from bipolar cells to ganglion cells, we measured the effect of uptake inhibitors on EPSCs evoked by direct electrical stimulation of bipolar cells. Figure $3 A$ shows the effect of PDC $(300 \mu \mathrm{M})$ on AMPA receptor-mediated EPSCs recorded at a holding potential of $-52 \mathrm{mV}$. PDC dramatically prolonged the current decay. Figure $3 B$ shows the initial portion 


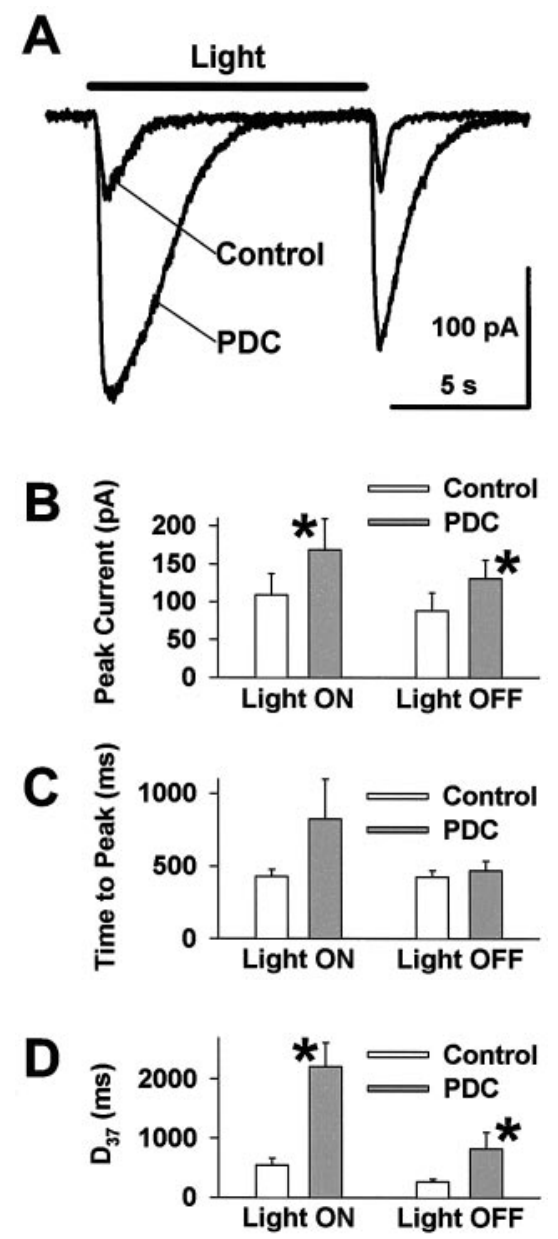

Figure 2. The glutamate uptake inhibitor PDC increased the amplitude and duration of light-evoked, AMPA receptor-mediated ganglion cell EPSCs. $A$, Light responses were recorded from an ON-OFF ganglion cell with and without $300 \mu \mathrm{M}$ PDC. $B$, PDC increased the peak current for both the $\mathrm{ON}$ response (control $=-109 \pm 28 \mathrm{pA} ; \mathrm{PDC}=-169 \pm 40 \mathrm{pA}$; $n=7 ; p=0.01$ ) and the OFF response (control $=-88 \pm 24 \mathrm{pA}$; PDC $=$ $-131 \pm 24 \mathrm{pA} ; p=0.04)$. Asterisks indicate a significant difference between control and PDC here and in subsequent figures. $C$, PDC lengthened the time from light onset to the peak of the ON response (control $=430 \pm 47 \mathrm{msec} ;$ PDC $=826 \pm 273 \mathrm{msec}$ ), but the effect did not reach significance $(p=0.09)$. The drug had little effect on the time from light offset to the peak of the OFF response (control $=427 \pm 44 \mathrm{msec}$; $\mathrm{PDC}=470 \pm 65$ msec; $p=0.18) . D$, PDC prolonged the $100-37 \%$ decay time $\left(D_{37}\right)$ for the ON response (control $=545 \pm 112 \mathrm{msec}$; PDC $=$ $2214 \pm 396 \mathrm{msec} ; p=0.001)$ and the OFF response (control $=264 \pm 45$ msec; PDC $=820 \pm 281 \mathrm{msec} ; p=0.03$ ). Cells were held at $-75 \mathrm{mV}$. For these experiments and those illustrated in subsequent figures showing AMPA receptor-mediated EPSCs, all extracellular solutions contained $150 \mu \mathrm{M}$ picrotoxin, $10 \mu \mathrm{M}$ strychnine, and $50 \mu \mathrm{M}$ D-AP-5.

of the EPSCs on an expanded time scale. The early phase was only slightly affected, whereas the late phase was greatly enhanced. In 12 cells, PDC did not significantly affect the peak current (Fig. 3C), slightly increased the time to peak (Fig. 3D), and greatly prolonged the decay time (Fig. $3 E$ ). Similar results were obtained with the glutamate uptake inhibitor D,L-threo- $\beta$ hydroxyaspartic acid (THA, $300 \mu \mathrm{M}$ ), which increased $D_{37}$ from $48 \pm 25$ to $1165 \pm 400 \mathrm{msec}(n=7 ; p=0.02)$. These decay times, both with and without the uptake inhibitor, were shorter than those obtained in the PDC studies. This difference may have resulted from the use of weaker stimuli $(2.3 \pm 0.6 \mu \mathrm{A})$ than those used in the PDC studies $(4.8 \pm 0.3 \mu \mathrm{A})$.

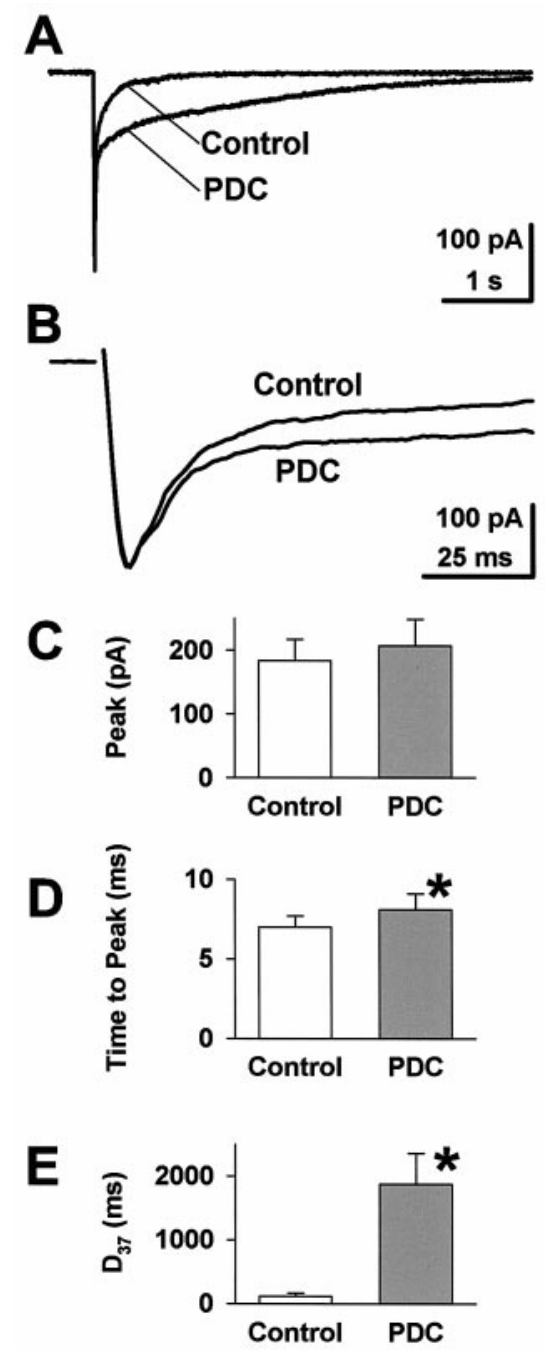

Figure 3. PDC prolonged monosynaptic AMPA receptor-mediated ganglion cell EPSCs evoked by electrical stimulation of bipolar cells. $A$, Complete decay of currents recorded with and without $300 \mu \mathrm{M}$ PDC is shown. $B$, The early phase of the same currents is shown. $C$, PDC did not significantly affect the peak current $($ control $=-184 \pm 33 \mathrm{pA}$; PDC $=$ $-207 \pm 42 \mathrm{pA} ; n=12 ; p=0.11) . D$, PDC slightly increased the time to peak (control $=7.0 \pm 0.7 \mathrm{msec} ; \mathrm{PDC}=8.1 \pm 1.0 \mathrm{msec} ; p=0.03) . E, \mathrm{PDC}$ greatly prolonged the decay time $\left(D_{37}\right)($ control $=111 \pm 52 \mathrm{msec} ; \mathrm{PDC}=$ $1868 \pm 485 \mathrm{msec} ; p=0.001)$. Cells were held at $-52 \mathrm{mV}$.

The effect of uptake inhibitors on EPSCs evoked by electrical stimuli does not seem to be dependent on a total amount of glutamate release in excess of that obtained with light stimuli. The charge transfer of the control stimulus-evoked EPSCs in the PDC studies was $-29 \pm 6 \mathrm{pC}$, whereas that of our control light responses was $-62 \pm 10 \mathrm{pC}$ for the $\mathrm{ON}$ response and $-28 \pm 7 \mathrm{pC}$ for the OFF response. The charge transfer of the average mEPSC at the holding potential of $-75 \mathrm{mV}$ was $-26 \pm 1 \mathrm{fC}(n=8)$. Thus, the average stimulus-evoked EPSC and the OFF light response both represent $\sim 1100$ times the quantal charge transfer, whereas the ON light response represents $\sim 2400$ times the quantal charge transfer. We caution that these values are unlikely to represent the actual quantal content, because of the possibility of nonlinear interactions between quanta.

Because our electrical stimuli excite bipolar cells directly, the effect of uptake inhibitors on stimulus-evoked EPSCs probably resulted from inhibition of glutamate clearance from the IPL. 
PDC did not affect the bipolar cell voltage response elicited by an electrical stimulus, because the integrated response in PDC was $102 \pm 6 \%$ of control $(n=8)$. However, glutamate accumulation in the OPL will affect the bipolar cell resting potential, perhaps altering the amount or time course of glutamate release. Additional experiments were performed to determine whether this effect is required for prolongation of ganglion cell EPSCs.

Prolongation of ganglion cell EPSCs by uptake inhibitors is not dependent on activation of glutamate receptors on presynaptic bipolar cells

To determine whether an OPL action is necessary for prolongation of ganglion cell EPSCs by uptake inhibitors, we blocked the effects of glutamate on the receptors that mediate synaptic input to bipolar cell dendrites. AMPA and kainate receptors on OFF bipolar cells were blocked with NBQX $(5 \mu \mathrm{M})$, and mGluR6 on ON bipolar cells was tonically activated with L-AP-4 (1 $\mu \mathrm{M})$, preventing any change in activation by synaptic glutamate. Because salamander bipolar cells do not have functional NMDA receptors (Slaughter and Miller, 1983), these could be left unblocked. Figure $4 A$ shows the effect of PDC $(300 \mu \mathrm{M})$ on NMDA receptor-mediated, stimulus-evoked ganglion cell EPSCs recorded under these conditions. In seven cells, PDC significantly increased the peak current (Fig. 4B), lengthened the time to peak (Fig. 4C), and prolonged the current decay (Fig. 4D). Because PDC may interact with NMDA receptors, we also performed similar experiments using sodium-free, lithium-based extracellular solution to inhibit sodium-dependent glutamate uptake (Fig. $4 E$ ). Our results were similar to those obtained with PDC. These studies confirm that glutamate uptake in the IPL is necessary for rapid termination of ganglion cell EPSCs.

\section{Blocking salamander excitatory amino acid transporter 2 subtypes does not affect ganglion cell EPSCs}

In many systems, neurotransmitter is transported back into presynaptic terminals (Cooper et al., 1996). Salamander bipolar cells have been shown to express two subtypes of excitatory amino acid transporter 2 (sEAAT2A and sEAAT2B). When expressed in oocytes, both sEAAT2s are blocked by low concentrations of dihydrokainate (DHK), which does not affect the other salamander retinal transporters at concentrations $<1 \mathrm{~mm}$ (Eliasof et al., 1998). To determine the functional role of these transporters, we compared the effects of DHK $(300 \mu \mathrm{M})$ and PDC $(300 \mu \mathrm{M})$ on AMPA receptor-mediated ganglion cell EPSCs (Fig. $5 A$ ). In six cells, DHK had no significant effect on the EPSC decay (Fig. $5 B$ ), although it did produce a small, steady inward current (Fig. $5 C$ ). Thus, sEAAT2 subtypes do not affect ganglion cell EPSCs, whereas other glutamate transporter species have a large effect on excitatory responses in the same cells. Because DHK is known to cause glutamate accumulation at cone photoreceptor synapses (Eliasof and Werblin, 1993; Yang and Wu, 1997; Gaal et al., 1998), these results provide further evidence that the effect of other uptake inhibitors on stimulus-evoked ganglion cell EPSCs does not originate in the outer plexiform layer.

\section{Glutamate uptake has little effect on spontaneous miniature EPSCs}

In some other systems, in which quanta may not interact significantly, glutamate uptake inhibitors do not affect EPSC kinetics (Isaacson and Nicoll, 1993; Sarantis et al., 1993; Maki et al., 1994; Tong and Jahr, 1994; but see Barbour et al., 1994). Uptake inhibitors have not been reported to prolong the decay of minia-

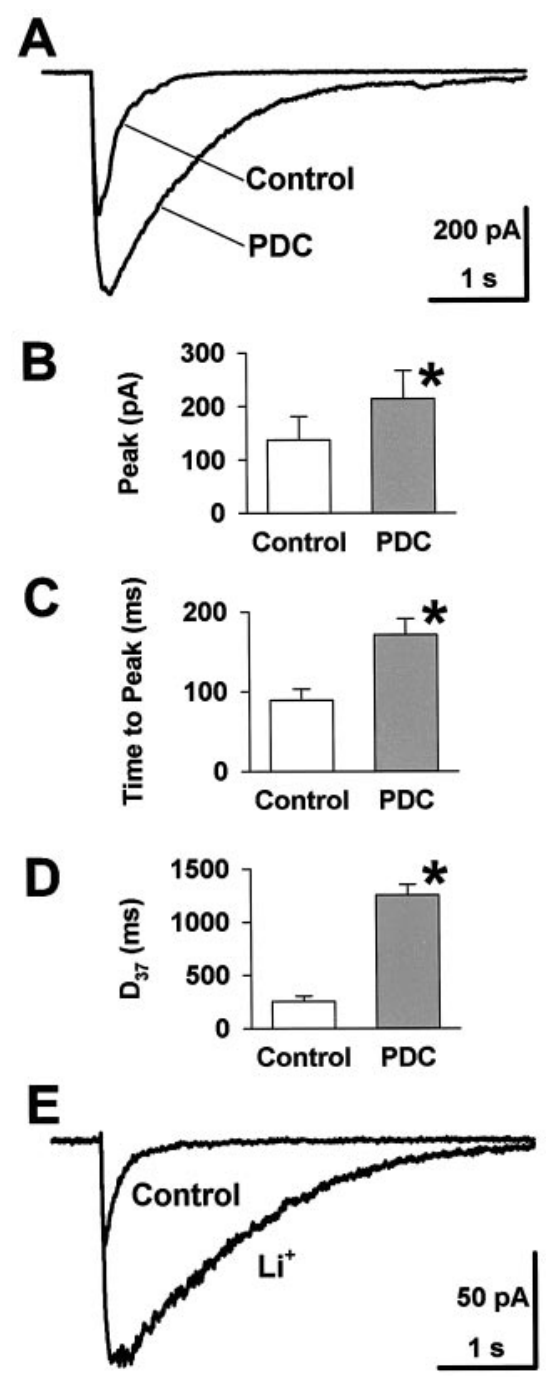

Figure 4. Inhibition of glutamate uptake increased the amplitude and duration of stimulus-evoked, NMDA receptor-mediated EPSCs. $A$, Currents recorded in the presence and in the absence of $300 \mu \mathrm{M}$ PDC are shown. $B, \mathrm{PDC}$ increased the peak current (control $=-137 \pm 44 \mathrm{pA}$; $\mathrm{PDC}=-214 \pm 53 \mathrm{pA} ; n=7 ; p=0.006) . C$, PDC increased the time to peak (control $=89 \pm 14 \mathrm{msec}$; PDC $=171 \pm 20 \mathrm{msec} ; p=0.002) . D$ PDC increased the decay time $\left(D_{37}\right)$ (control $=256 \pm 49 \mathrm{msec} ; \mathrm{PDC}=1257 \pm$ $95 \mathrm{msec} ; p=0.00003)$. $E$, Currents recorded in normal extracellular solution (see Materials and Methods) and in solution containing $115 \mathrm{~mm}$ $\mathrm{Li}^{+}$and $0 \mathrm{Na}^{+}$are shown. The $\mathrm{Li}^{+}$solution prolonged $D_{37}$ from $168 \pm$ 28 to $1268 \pm 330 \mathrm{msec}(n=5 ; p=0.02)$. Cells were held at $-30 \mathrm{mV}$. For these experiments, all extracellular solutions contained $150 \mu \mathrm{M}$ picrotoxin, $10 \mu \mathrm{M}$ strychnine, $5 \mu \mathrm{M} \mathrm{NBQX}$, and $1 \mu \mathrm{M}$ L-AP-4, blocking any effects of extracellular glutamate accumulation on AMPA and KA receptors or on mGluR6 on bipolar cell dendrites in the outer plexiform layer.

ture synaptic currents in neurons, consistent with the hypothesis that diff usion is sufficient to clear transmitter rapidly from a single neuronal synapse. However, acetylcholinesterase inhibitors do prolong mEPSCs at the neuromuscular junction (Gage and Armstrong, 1968; Hartzell et al., 1975), perhaps because diffusion of transmitter from this large synapse is somewhat slower. To determine whether glutamate transporter function is necessary for the rapid clearance of single quanta from ganglion cell synapses, we measured the effect of PDC on spontaneous mEPSCs. As for evoked AMPA receptor-mediated EPSCs, GABA, glycine, and NMDA receptors were blocked with picrotoxin, strychnine, and 


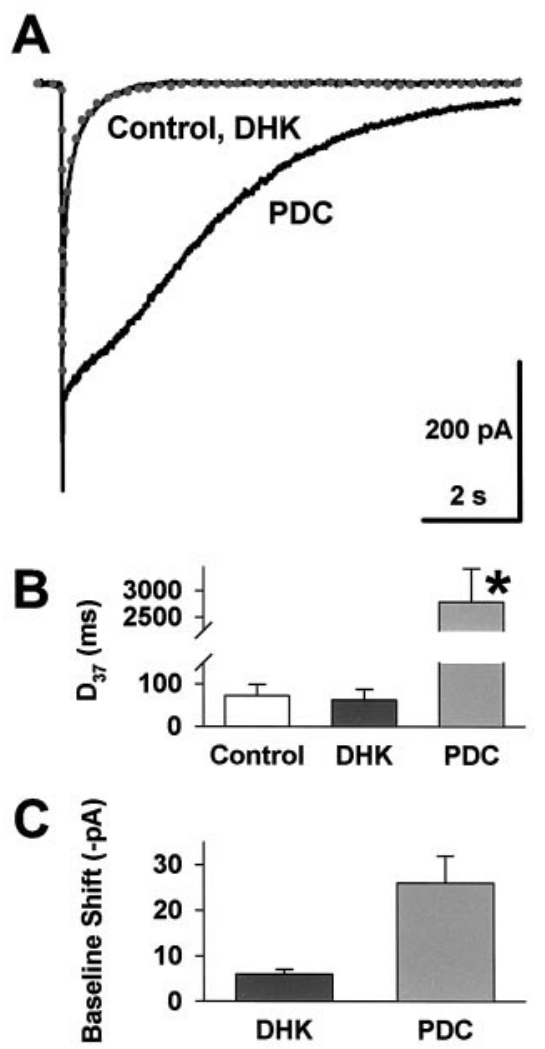

Figure 5. The sEAAT2 inhibitor DHK did not affect stimulus-evoked, AMPA receptor-mediated EPSCs. $A$, Currents recorded in control solution, in $300 \mu \mathrm{M}$ DHK (gray circles), and in $300 \mu \mathrm{M}$ PDC are shown. $B$, The decay time $\left(D_{37}\right)$ was not affected by DHK but was increased by PDC (control $=72 \pm 27 \mathrm{msec} ;$ DHK $=62 \pm 26 \mathrm{msec} ;$ PDC $=2791 \pm 632 \mathrm{msec}$; $n=6)$. $C$, DHK elicited a small, steady inward current $(-6.0 \pm 0.9 \mathrm{pA}$; $n=6)$, whereas PDC gave a somewhat larger steady current $(-26 \pm 7 \mathrm{pA})$ in the same cells. The holding potential was -52 to $-75 \mathrm{mV}$.

D-AP-5, respectively. Figure $6 A$ shows the effect of PDC (300 $\mu \mathrm{M})$ on average mEPSCs in a ganglion cell. In eight cells held at -75 $\mathrm{mV}$, the peak current was not affected by PDC (Fig. 6B). The time to peak was slightly prolonged (Fig. $6 C$ ), but the decay time $\left(D_{37}\right)$ was not significantly altered (Fig. 6D). The small effect of PDC on mEPSC kinetics suggests that diffusion can quickly clear a quantum of glutamate from a single ganglion cell synapse. The large effect of glutamate uptake inhibitors on evoked EPSCs indicates that these multiquantal responses must not arise from linear summation of independent quantal events. Rather, the interaction of multiple quanta must give rise to an additional component of the response that is limited by glutamate uptake.

\section{The kinetics of ganglion cell EPSCs depend on quantal content}

If multiple quanta interact during evoked EPSCs, one might expect that the decay kinetics would depend on the number of quanta released. To test this hypothesis, we reduced glutamate release by several methods. First, we lowered the $\mathrm{Ca}^{2+} / \mathrm{Mg}^{2+}$ ratio of the extracellular solution, keeping the total divalent cation concentration constant. Figure $7 A$ shows stimulus-evoked, AMPA receptor-mediated EPSCs recorded in normal $\mathrm{Ca}^{2+}(2$ $\mathrm{mM})$ and in low $\mathrm{Ca}^{2+}(0.5 \mathrm{mM})$. When the currents are scaled to the same peak amplitude (Fig. $7 B$ ), it is apparent that the current decay was faster in low $\mathrm{Ca}^{2+}$. On average, $D_{37}$ was $52 \pm 15 \mathrm{msec}$ in normal $\mathrm{Ca}^{2+}$ and $22 \pm 6 \mathrm{msec}$ in low $\mathrm{Ca}^{2+}(n=7 ; p=0.04)$.

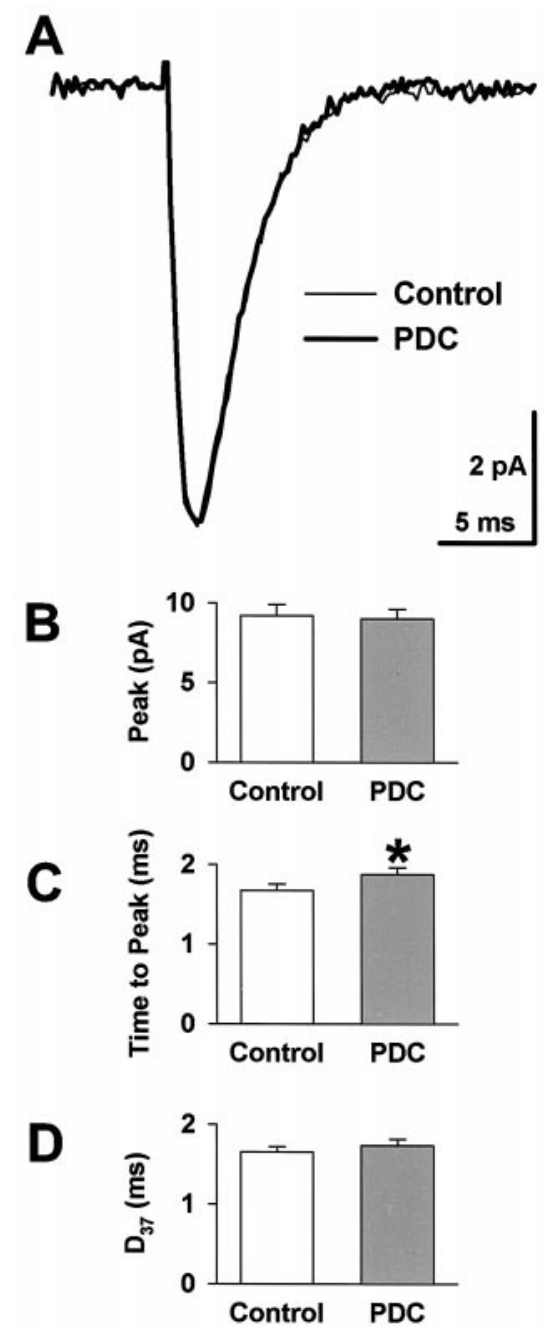

Figure 6. PDC had little effect on spontaneous mEPSCs. A, Currents recorded in control solution (thin line) and in $300 \mu \mathrm{M}$ PDC (thick line) are shown. $B$, PDC did not affect the mean event amplitude (control = $-9.2 \pm 0.7 \mathrm{pA} ; \mathrm{PDC}=-9.0 \pm 0.6 \mathrm{pA} ; n=8$ cells). $C$, PDC slightly increased the mean time from event onset to peak (control $=1.67 \pm 0.08$ msec; PDC $=1.87 \pm 0.09 \mathrm{msec} ; p=0.01) . D$, PDC did not significantly affect the mean decay time $\left(D_{37}\right)($ control $=1.65 \pm 0.07 \mathrm{msec}$; PDC $=$ $1.73 \pm 0.08 \mathrm{msec} ; p=0.16$ ). Cells were held at $-75 \mathrm{mV}$. The small inflection at the onset of each mEPSC is an artifact resulting from alignment of individual events by the event onset (defined as the first data point left of the peak at $<0.5 \%$ of the peak amplitude). None of our results are dependent on mEPSC alignment, because all measures reported are mean values for individual events.

We were concerned that changing the $\mathrm{Ca}^{2+} / \mathrm{Mg}^{2+}$ ratio might alter the time course of glutamate release from bipolar cells. Thus, we sought another means of varying quantal content, preferably without affecting calcium influx into presynaptic terminals. We found that ganglion cell EPSCs show significant paired-pulse depression. When two stimuli were delivered at a 2 sec interval, the second response was depressed by $39 \pm 2 \%(n=17)$. For cells subjected to paired stimuli at intervals of $0.3-60 \mathrm{sec}$, the peak current recovered with a single exponential time constant of $13 \pm$ $3 \sec (n=6)$. Because ganglion cell EPSCs have a slow component, we performed subsequent experiments with a 2 sec interstimulus interval, which allowed the first EPSC to decay to baseline before the second stimulus was applied.

To determine whether depression at this interval results from 

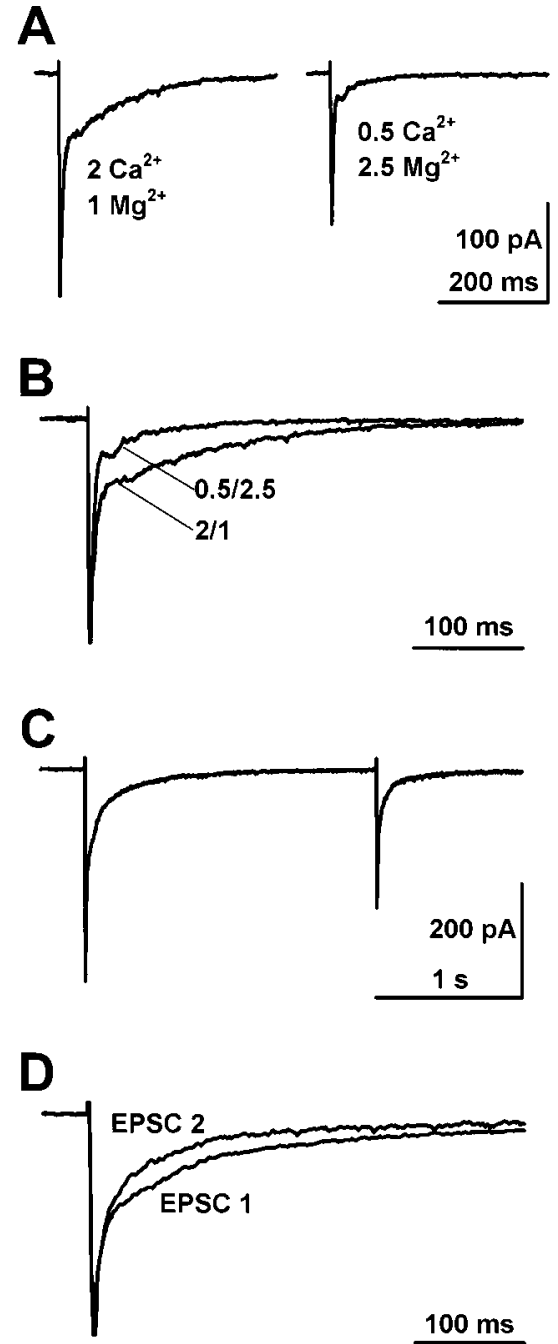

Figure 7. The decay of stimulus-evoked, AMPA receptor-mediated EPSCs became faster when glutamate release was reduced. $A$, Currents recorded in control extracellular solution $\left(2 \mathrm{mM} \mathrm{Ca}^{2+}\right.$ and $\left.1 \mathrm{mM} \mathrm{Mg}^{2+}\right)$ and in low-calcium solution $\left(0.5 \mathrm{~mm} \mathrm{Ca}^{2+}\right.$ and $\left.2.5 \mathrm{mM} \mathrm{Mg}^{2+}\right) . B$, The same currents, scaled to the same peak amplitude. The current decay was faster in low-calcium solution. $C$, Currents evoked by paired stimuli at a $2 \mathrm{sec}$ interval. $D$, Currents evoked by the first and second stimuli, scaled to the same peak amplitude. The second, depressed EPSC decayed faster than did the first response. Cells were held at $-75 \mathrm{mV}$.

decreased glutamate release from presynaptic terminals or from postsynaptic receptor desensitization, we measured the effect of paired stimuli on NMDA receptor-mediated EPSCs. To prevent calcium-dependent desensitization of NMDA receptors, cells were held at $+30 \mathrm{mV}$ to reduce calcium influx, and the electrode solution contained $10 \mathrm{~mm}$ BAPTA. Under these conditions, the second NMDA receptor-mediated EPSC was depressed by $53 \pm$ $4 \%$ (peak current; $n=5$ ). In the same cells, AMPA receptormediated EPSCs were depressed by $36 \pm 8 \%$. These results strongly support a presynaptic mechanism of depression at the 2 sec interstimulus interval. It is possible that a postsynaptic component of depression would also be observed at shorter intervals (Trussell et al., 1993). Interestingly, the peak NMDA receptormediated EPSC may be more sensitive than the peak AMPA receptor-mediated response to a reduction in quantal content. This result may be consistent with the proposed extrasynaptic localization of NMDA receptors on retinal ganglion cells (Taylor et al., 1995; Matsui et al., 1998).

Like low calcium, paired-pulse depression accelerated the EPSC decay. Figure $7 C$ shows paired AMPA receptor-mediated EPSCs, and Figure $7 D$ shows the two currents scaled to the same peak amplitude. The depressed EPSC decayed faster than did the first, full-size current. On average, $D_{37}$ was reduced from $31 \pm 6$ $\mathrm{msec}$ for the first EPSC to $16 \pm 2 \mathrm{msec}$ for the second response $(n=17 ; p=0.004)$.

We also reduced glutamate release by adjusting the stimulus strength. In seven cells, lowering the stimulus current from 5 to $2.5 \mu \mathrm{A}$ reduced the amplitude of NMDA receptor-mediated EPSCs (recorded at $-30 \mathrm{mV}$ ) by $71 \pm 5 \%$ and shortened $D_{37}$ from $219 \pm 48$ to $110 \pm 16 \mathrm{msec}(p=0.015)$. These results confirm that lowering quantal content without changing the $\mathrm{Ca}^{2+} / \mathrm{Mg}^{2+}$ ratio speeds the EPSC decay, consistent with the hypothesis that the interaction of multiple quanta prolongs ganglion cell EPSCs.

\section{The late phase of multiquantal AMPA receptor-mediated EPSCs is voltage dependent}

If the interaction of multiple quanta causes prolonged activation of postsynaptic receptors, AMPA receptors are likely to desensitize, limiting the late phase of the EPSC. Reducing desensitization with cyclothiazide dramatically prolongs ganglion cell EPSCs (Lukasiewicz et al., 1995). However, cyclothiazide has been reported to increase glutamate release (Diamond and Jahr, 1995; but see von Gersdorff et al., 1998) and enhances the apparent affinity of agonists for at least some AMPA receptors (Patneau et al., 1993; Yamada and Tang, 1993). It has been reported that the extent to which AMPA receptors desensitize is also reduced by positive holding potentials (Patneau et al., 1993; Raman and Trussell, 1995). Thus, we compared AMPA receptor-mediated ganglion cell EPSCs recorded at -75 and $+75 \mathrm{mV}$. MK-801 (2 $\mu \mathrm{M}$ ) was added to the extracellular solution in addition to D-AP-5 $(50 \mu \mathrm{M})$ to block a small NMDA receptor-mediated current that was often observed at $+75 \mathrm{mV}$ with either antagonist alone. To maintain stable recordings, we stepped cells to $+75 \mathrm{mV} 2 \mathrm{sec}$ before the stimulus and returned the cells to $-75 \mathrm{mV}$ at the end of the record. Currents elicited by voltage steps without stimuli were subtracted.

Figure $8 A$ shows stimulus-evoked, AMPA receptor-mediated EPSCs recorded at -75 and $+75 \mathrm{mV}$, both plotted in the positive orientation and scaled to compensate for a slight difference in peak amplitude. On average, the peak current at $+75 \mathrm{mV}$ was $96 \pm 8 \%$ of the $-75 \mathrm{mV}$ peak $(n=12 ; p=0.15)$. The amplitude of the late phase of the EPSC (measured $50 \mathrm{msec}$ after the stimulus and normalized to the peak current) was significantly increased at $+75 \mathrm{mV}$ (Fig. $8 B$ ). However, the current decay from the $50 \mathrm{msec}$ point $\left(D_{37 \text { LATE}}\right)$ was not prolonged (Fig. $8 C$ ). The voltage dependence of these EPSCs did not result from activation of NMDA receptors, because the currents were $95 \pm 1 \%$ blocked by the AMPA receptor antagonist NBQX at $+75 \mathrm{mV}(n=10)$. These results suggest that the amplitude of the late phase of the AMPA receptor-mediated EPSC may be limited by desensitization.

To investigate the interaction of AMPA receptor desensitization and glutamate uptake, we determined the effect of the holding potential $(+50 \mathrm{vs}-50 \mathrm{mV})$ on EPSCs recorded in the presence and in the absence of PDC $(300 \mu \mathrm{M})$. In seven cells, the amplitude of the late phase was significantly increased at +50 $\mathrm{mV}$, both in control solution $(145 \pm 7 \%$ of the $-50 \mathrm{mV}$ value; $p=$ 

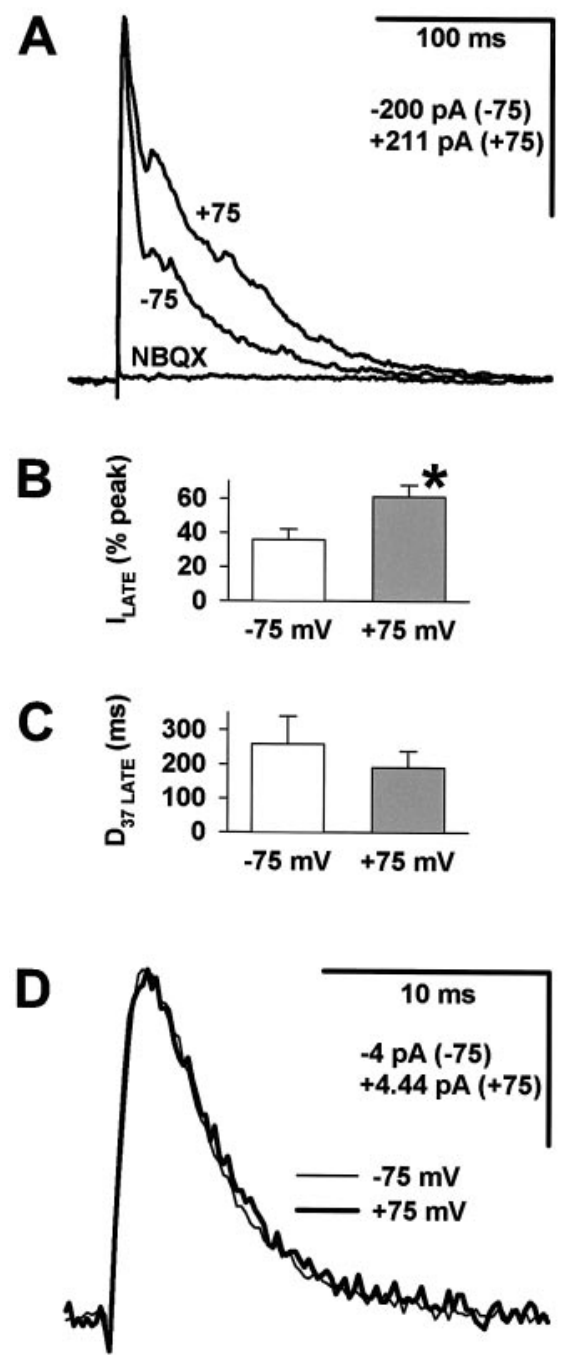

Figure 8. Holding ganglion cells at $+75 \mathrm{mV}$ increased the amplitude of the late phase of multiquantal AMPA receptor-mediated EPSCs. $A$, Evoked EPSCs recorded at $-75 \mathrm{mV}$ in control solution, at $+75 \mathrm{mV}$ in control solution, and at $+75 \mathrm{mV}$ in $5 \mu \mathrm{M} \mathrm{NBQX}$ are shown. The slightly different current scales for -75 and $+75 \mathrm{mV}$ are chosen to superimpose the EPSC peaks in the absence of NBQX. $B$, The amplitude of the late phase $\left(I_{\text {LATE }}\right.$, measured $50 \mathrm{msec}$ after the stimulus) was greater at +75 $\mathrm{mV}(61 \pm 7 \%$ of peak; $n=12)$ than at $-75 \mathrm{mV}(36 \pm 6 \%$ of peak $)(p=$ 0.0001). $C$, The decay of the late phase ( $D_{37 \text { LATE}}$, measured from $50 \mathrm{msec}$ after the stimulus) was not significantly different at $-75 \mathrm{mV}(259 \pm 81$ $\mathrm{msec})$ and at $+75 \mathrm{mV}(190 \pm 48 \mathrm{msec})(p=0.10)$. $D$, Average mEPSCs from a cell held at $-75 \mathrm{mV}$ (thin line) and at $+75 \mathrm{mV}$ (thick line), scaled to the same peak amplitude, are shown. In six cells, the holding potential had little effect on the mean event amplitude $(-9.0 \pm 1.2 \mathrm{pA}$ at $-75 \mathrm{mV}$; $9.4 \pm 1.6 \mathrm{pA}$ at $+75 \mathrm{mV} ; p=0.26)$, the time to peak $(1.8 \pm 0.1 \mathrm{msec}$ at $-75 \mathrm{mV} ; 2.0 \pm 0.1 \mathrm{msec}$ at $+75 \mathrm{mV} ; p=0.10)$, or the decay time $\left(D_{37}\right)$ $(1.9 \pm 0.1 \mathrm{msec}$ at $-75 \mathrm{mV} ; 2.1 \pm 0.1 \mathrm{msec}$ at $+75 \mathrm{mV} ; p=0.07)$. For these experiments, all extracellular solutions contained $150 \mu \mathrm{M}$ picrotoxin, $10 \mu \mathrm{M}$ strychnine, $50 \mu \mathrm{M}$ D-AP-5, and $2 \mu \mathrm{M} \mathrm{MK}-801$ to ensure complete blockade of NMDA receptors.

$0.001)$ and in PDC $(126 \pm 7 \% ; p=0.01)$. The late phase decay was greatly prolonged by PDC [10 ( \pm 2$)$-fold at $-50 \mathrm{mV}]$. However, $D_{37}$ LATE was only slightly affected by the $+50 \mathrm{mV}$ holding potential, either in control solution (108 $\pm 7 \%$ of the -50 $\mathrm{mV}$ value; $p=0.44)$ or in PDC $(130 \pm 18 \% ; p=0.16)$. These results suggest that the effects of AMPA receptor desensitization and glutamate uptake are distinct and primarily independent.
Desensitization limits the amplitude of the late phase of the EPSC, whereas glutamate uptake controls the response duration.

The similarity of peak EPSC amplitudes at -75 and $+75 \mathrm{mV}$ suggested that quantal currents are unlikely to have significant voltage dependence. Because mEPSCs rise and fall to near baseline within the rise time of stimulus-evoked EPSCs, almost any change in mEPSC kinetics would affect the peak of an evoked response. Thus, the voltage dependence of ganglion cell EPSCs must arise from the interaction of multiple quanta. To confirm this hypothesis, we compared mEPSCs recorded at -75 and +75 $\mathrm{mV}$ (Fig. 8D). Analysis was restricted to those cells with baseline noise sufficiently low that mEPSCs could be readily identified at $+75 \mathrm{mV}$. To minimize sampling bias caused by the difficulty of detecting the smallest events at $+75 \mathrm{mV}$, we increased the amplitude threshold for event detection until the mEPSC amplitude distributions were similar at the two holding potentials. We found that the voltage had no significant effect on the mEPSC amplitude, time to peak, or decay time, confirming that the interaction of multiple quanta gives rise to the large voltage dependence of evoked EPSCs.

These results are consistent with the hypothesis that mEPSCs and multiquantal responses decay by distinct mechanisms. mEPSCs may terminate primarily by receptor deactivation after rapid glutamate clearance from the synaptic cleft, as suggested for glutamatergic synapses on cultured retinal ganglion cells (Taschenberger et al., 1995). Because the holding potential had only small, nonsignificant effects on mEPSC amplitude and duration, deactivation of ganglion cell AMPA receptors probably has little voltage dependence. Unlike mEPSCs, multiquantal responses seem to be limited by voltage-dependent AMPA receptor desensitization and ultimately terminated by glutamate uptake.

\section{DISCUSSION}

We found that glutamate uptake inhibitors greatly prolonged ganglion cell EPSCs evoked by light stimuli or by electrical stimulation of bipolar cells, indicating that uptake in the IPL is important for termination of the ganglion cell response. Because uptake inhibition had little effect on mEPSCs, nonlinear interaction of multiple quanta must underlie the component of the response that is limited by uptake. Two of our results suggest that interaction between quanta can occur even when uptake functions normally. The decay of stimulus-evoked EPSCs was dependent on quantal content, and a component of the evoked EPSC had significant outward rectification, whereas the mEPSCs did not. These results suggest that multiple quanta of glutamate may interact with common postsynaptic receptor domains, perhaps because of spillover between synapses.

\section{Effects of slow transmitter clearance and spillover in other central neurons}

Synaptic currents in several other types of central neurons appear to be prolonged by slow transmitter clearance. In some systems, a specialized synaptic morphology may facilitate pooling of multiple quanta or restrict clearance by diffusion. Neurons of the chick nucleus magnocellularis receive calyceal synapses at which multiple release sites empty into a common synaptic cleft (Rubel and Parks, 1988). In these cells, reducing extracellular $\mathrm{Ca}^{2+}$ shortened the decay of AMPA receptor-mediated EPSCs recorded in the presence of cyclothiazide, suggesting that interaction of multiple quanta prolongs the current decay (Trussell et al., 1993). Even in the absence of cyclothiazide, the AMPA receptor-mediated EPSCs of these cells had a small slow component (Otis et 
al., 1996). This component was observed only in high quantal content responses, had the outward rectification of a steady-state AMPA receptor-mediated current, and was enhanced by glutamate uptake inhibitors. When uptake was blocked, the current often showed a plateau or hump (which we also observed in some ganglion cells) before decaying to baseline. Modeling studies suggested that the slow component results from a slow phase of glutamate clearance after release from multiple sites. The hump in the EPSC decay appears to occur when the glutamate concentration falls to the peak of the biphasic concentration-response relation for steady-state activation of AMPA receptors.

Similar but more striking results were obtained for unipolar brush cells in the cerebellum, which receive unusually large synaptic contacts from mossy fiber terminals (Rossi et al., 1995). The EPSCs of these cells usually had a fast AMPA receptormediated component and a slow component mediated by AMPA and NMDA receptors. The portion of the slow component mediated by AMPA receptors usually rose slowly to a peak before decaying to baseline, reminiscent of the less pronounced hump observed by Otis et al. (1996). The slow component was prolonged when glutamate uptake was inhibited with PDC (Kinney et al., 1997).

In some other cells, the synaptic current is prolonged after high quantal content release under certain experimental conditions, despite the lack of any known synaptic specialization for retaining transmitter. Mennerick and Zorumski (1995) found that reducing glutamate release from cultured hippocampal neurons shortened the decay of AMPA receptor-mediated EPSCs recorded in the presence of cyclothiazide. They also observed that inhibition of glutamate uptake prolonged high quantal content EPSCs but had less effect on responses of reduced quantal content and no effect on mEPSCs. It was suggested that glutamate spillover might contribute to these effects. Isaacson et al. (1993) found that depression of EPSCs in hippocampal CA1 pyramidal cells was mediated by activation of presynaptic $\mathrm{GABA}_{\mathrm{B}}$ receptors. This heterosynaptic effect indicated that GABA can spill over between synapses. Application of a GABA uptake inhibitor increased the heterosynaptic depression. Uptake inhibition also prolonged IPSCs evoked by strong stimuli but had little effect on those evoked by weak stimuli.

We found that the decay of ganglion cell EPSCs is prolonged under conditions of high quantal content. The effect of uptake inhibition must also depend on quantal content, because PDC prolonged evoked EPSCs but not mEPSCs. We attempted to determine whether reducing quantal content lessened the effect of PDC on evoked EPSCs, but our results were highly variable. In some cells, PDC prolonged small EPSCs less than larger responses, but in other cells, very small responses developed a large slow component on application of the uptake inhibitor. It is tempting to speculate that this resulted from spillover of glutamate from release sites not directly apposed to the recorded cell.

\section{Molecular and cellular basis of glutamate clearance from ganglion cell synapses}

Five subtypes of glutamate transporters have been cloned from salamander retina and localized by immunohistochemistry (Eliasof et al., 1998). All are present in the IPL. The GLAST homolog sEAAT1 is found primarily in Müller cells. The GLT-1 homolog sEAAT2A is located in Müller cells and some bipolar and amacrine cells. A related transporter, sEAAT2B, is present in OFF bipolar cells. Two novel retinal transporters, sEAAT5A and
sEAAT5B, appear to be expressed in Müller cells and in neurons of all cell layers.

Our ability to determine which transporters clear glutamate from ganglion cell synapses is limited by the lack of specific antagonists. Nonspecific inhibitors such as PDC (Bridges et al., 1991; Griffiths et al., 1994) and THA appear to act as competitive substrates for all sodium-dependent glutamate transporters (Arriza et al., 1994). DHK is a selective, nontransported, competitive inhibitor of EAAT2 subtypes, including sEAAT2A and sEAAT2B, expressed in Xenopus oocytes (Arriza et al., 1994; Eliasof et al., 1998). Because these transporters are present on bipolar cells, they might be expected to clear glutamate from ganglion cell synapses. However, DHK did not significantly prolong ganglion cell EPSCs. It remains possible that other transporters on bipolar cell terminals remove synaptically released glutamate. We do not believe that ganglion cells are likely to contribute significantly to glutamate clearance from the IPL. In preliminary experiments, perfusion of the retinal slice with the glutamate transporter substrate D-aspartate gave little or no current in ganglion cells, even when the pipette solution contained thiocyanate to enhance the transporter-associated anion conductance (Eliasof and Jahr, 1996). As in other systems (Mennerick and Zorumski, 1994; Bergles and Jahr, 1998), glial uptake may be important for the clearance of glutamate in the inner plexiform layer. Müller glia are known to take up glutamate (Barbour et al., 1991; Yang and Wu, 1997) and have processes that surround retinal cells and synapses (Newman and Reichenbach, 1996). Thus, they may be responsible for the glutamate uptake that shapes ganglion cell EPSCs.

\section{Interaction of glutamate uptake and AMPA receptor desensitization}

Glutamate uptake and AMPA receptor desensitization both limit the late phase of ganglion cell EPSCs, but their effects are kinetically distinct. This became evident when we analyzed the late phase of the response, starting $50 \mathrm{msec}$ after the stimulus. Blocking glutamate uptake with PDC greatly prolonged the late phase. Reducing AMPA receptor desensitization by holding the cell at +50 to $+75 \mathrm{mV}$ increased the amplitude of the late phase but did not significantly affect its rate of decay. All AMPA receptors studied to date have desensitization rates much faster than the late phase of ganglion cell EPSCs (Colquhoun et al., 1992; Raman and Trussell, 1992; Eliasof and Jahr, 1997). For cultured rat ganglion cells, the AMPA receptor desensitization time constant was $2.9 \mathrm{msec}$ (Taschenberger et al., 1995). If the late phase of glutamate clearance is much slower than the kinetic transitions of AMPA receptors, the synaptic current will represent a steady-state glutamate response, during which a large fraction of the receptor population will be desensitized. The response will then decay as a function of the glutamate concentration and the steady-state concentration-response curve (Otis et al., 1996; Kinney et al., 1997).

\section{Physiological significance}

Inhibition of glutamate transporters greatly prolonged lightevoked EPSCs in ON-OFF ganglion cells, suggesting that uptake controls the duration of physiological responses. Although the effect of uptake inhibitors must be dependent on release of multiple quanta, it was not limited to responses of particularly 
high quantal content; even light responses with a peak amplitude $<10 \mathrm{pA}$ and stimulus-evoked responses of $<30 \mathrm{pA}$ were lengthened by PDC. By terminating each EPSC, glutamate uptake may facilitate ganglion cell responses to high-frequency stimuli. Uptake might also limit glutamate spillover between IPL sublaminae, thereby maintaining the separation between ON and OFF pathways. However, uptake is probably not efficient enough to prevent spillover completely. Our results suggest that multiple quanta of glutamate can interact within the IPL, giving rise to a slow component of the EPSC. Thus, diff use glutamate signals may contribute to physiological responses in the inner retina.

\section{REFERENCES}

Arriza JL, Fairman WA, Wadiche JI, Murdoch GH, Kavanaugh MP, Amara SG (1994) Functional comparisons of three glutamate transporter subtypes cloned from human motor cortex. J Neurosci 14:5559-5569.

Barbour B, Brew H, Attwell D (1991) Electrogenic uptake of glutamate and aspartate into glial cells isolated from the salamander (Ambystoma) retina. J Physiol (Lond) 436:169-193.

Barbour B, Keller BU, Llano I, Marty A (1994) Prolonged presence of glutamate during excitatory synaptic transmission to cerebellar Purkinje cells. Neuron 12:1331-1343.

Bergles DE, Jahr CE (1998) Glial contribution to glutamate uptake at Schaffer collateral-commissural synapses in the hippocampus. J Neurosci 18:7709-7716.

Bridges RJ, Stanley MS, Anderson MW, Cotman CW, Chamberlin AR (1991) Conformationally defined neurotransmitter analogues. Selective inhibition of glutamate uptake by one pyrrolidine-2,4-dicarboxylate diastereomer. J Med Chem 34:717-725.

Clements JD, Lester RAJ, Tong G, Jahr CE, Westbrook GL (1992) The time course of glutamate in the synaptic cleft. Science 258:1498-1501.

Colquhoun D, Jonas P, Sakmann B (1992) Action of brief pulses of glutamate on AMPA/kainate receptors in patches from different neurones of rat hippocampal slices. J Physiol (Lond) 458:261-287.

Cook PB, Lukasiewicz PD, McReynolds JS (1998) Action potentials are required for the lateral transmission of glycinergic transient inhibition in the amphibian retina. J Neurosci 18:2301-2308.

Cooper JR, Bloom FE, Roth RH (1996) The biochemical basis of neuropharmacology, 7th Edition. New York: Oxford UP.

Diamond JS, Jahr CE (1995) Asynchronous release of synaptic vesicles determines the time course of the AMPA receptor-mediated EPSC. Neuron 15:1097-1107.

Eccles JC, Jaeger JC (1958) The relationship between the mode of operation and the dimensions of the junctional regions at synapses and motor end-organs. Proc R Soc Lond [Biol] 148:38-56.

Eliasof S, Jahr CE (1996) Retinal glial cell glutamate transporter is coupled to an anionic conductance. Proc Natl Acad Sci USA 93:4153-4158.

Eliasof S, Jahr CE (1997) Rapid AMPA receptor desensitization in catfish cone horizontal cells. Vis Neurosci 14:13-18.

Eliasof S, Werblin F (1993) Characterization of the glutamate transporter in retinal cones of the tiger salamander. J Neurosci 13:402-411.

Eliasof S, Arriza JL, Leighton BH, Kavanaugh MP, Amara SG (1998) Excitatory amino acid transporters of the salamander retina: identification, localization, and function. J Neurosci 18:698-712.

Gaal L, Roska B, Picaud SA, Wu SM, Marc R, Werblin FS (1998) Postsynaptic response kinetics are controlled by a glutamate transporter at cone photoreceptors. J Neurophysiol 79:190-196.

Gage PW, Armstrong CM (1968) Miniature end-plate currents in voltage-clamped muscle fibre. Nature 218:363-365.

Griffiths R, Dunlop J, Gorman A, Senior J, Grieve A (1994) L-Transpyrrolidine-2,4-dicarboxylate and cis-1-aminocyclobutane-1,3dicarboxylate behave as transportable, competitive inhibitors of the high-affinity glutamate transporters. Biochem Pharmacol 47:267-274.

Hartzell HC, Kuffler SW, Yoshikami D (1975) Post-synaptic potentiation: interaction between quanta of acetylcholine at the skeletal neuromuscular synapse. J Physiol (Lond) 251:427-463.

Isaacson JS, Nicoll RA (1993) The uptake inhibitor L-trans-PDC en- hances responses to glutamate but fails to alter the kinetics of excitatory synaptic currents in the hippocampus. J Neurophysiol 70:2187-2190.

Isaacson JS, Solis JM, Nicoll RA (1993) Local and diffuse synaptic actions of GABA in the hippocampus. Neuron 10:165-175.

Kinney GA, Overstreet LS, Slater NT (1997) Prolonged physiological entrapment of glutamate in the synaptic cleft of cerebellar unipolar brush cells. J Neurophysiol 78:1320-1333.

Lagnado L, Gomis A, Job C (1996) Continuous vesicle cycling in the synaptic terminal of retinal bipolar cells. Neuron 17:957-967.

Lehre KP, Davanger S, Danbolt NC (1997) Localization of the glutamate transporter protein GLAST in rat retina. Brain Res 744:129-137.

Lukasiewicz PD, Roeder RC (1995) Evidence for glycine modulation of excitatory synaptic inputs to retinal ganglion cells. J Neurosci 15:4592-4601.

Lukasiewicz PD, Maple BR, Werblin FS (1994) A novel GABA receptor on bipolar cell terminals in the tiger salamander retina. J Neurosci 14:1201-1212.

Lukasiewicz PD, Lawrence JE, Valentino TL (1995) Desensitizing glutamate receptors shape excitatory synaptic inputs to tiger salamander retinal ganglion cells. J Neurosci 15:6189-6199.

Maki R, Robinson MB, Dichter MA (1994) The glutamate uptake inhibitor L-trans-pyrrolidine-2,4-dicarboxylate depresses excitatory synaptic transmission via a presynaptic mechanism in cultured hippocampal neurons. J Neurosci 14:6754-6762.

Matsui K, Hosoi N, Tachibana M (1998) Excitatory synaptic transmission in the inner retina: paired recordings of bipolar cells and neurons of the ganglion cell layer. J Neurosci 18:4500-4510.

Mennerick S, Zorumski CF (1994) Glial contributions to excitatory neurotransmission in cultured hippocampal cells. Nature 368:59-62.

Mennerick S, Zorumski CF (1995) Presynaptic influence on the time course of fast excitatory synaptic currents in cultured hippocampal cells. J Neurosci 15:3178-3192.

Mittman S, Taylor WR, Copenhagen DR (1990) Concomitant activation of two types of glutamate receptor mediates excitation of salamander retinal ganglion cells. J Physiol (Lond) 428:175-197.

Newman E, Reichenbach A (1996) The Müller cell: a functional element of the retina. Trends Neurosci 19:307-312.

Otis TS, Wu Y-C, Trussell LO (1996) Delayed clearance of transmitter and the role of glutamate transporters at synapses with multiple release sites. J Neurosci 16:1634-1644.

Patneau DK, Vyklicky L, Mayer ML (1993) Hippocampal neurons exhibit cyclothiazide-sensitive rapidly desensitizing responses to kainate. J Neurosci 13:3496-3509.

Raman IM, Trussell LO (1992) The kinetics of the response to glutamate and kainate in neurons of the avian cochlear nucleus. Neuron 9:173-186.

Raman IM, Trussell LO (1995) Concentration jump analysis of voltagedependent conductances activated by glutamate and kainate in neurons of the avian cochlear nucleus. Biophys J 69:1868-1879.

Rauen T, Rothstein JD, Wässle H (1996) Differential expression of three glutamate transporter subtypes in the rat retina. Cell Tissue Res 286:325-336.

Rossi DJ, Alford S, Mugnaini E, Slater NT (1995) Properties of transmission at a giant glutamatergic synapse in cerebellum: the mossy fiber-unipolar brush cell synapse. J Neurophysiol 74:24-42.

Rubel EW, Parks TN (1988) Organization and development of the avian brain-stem auditory system. In: Auditory function (Edelman GM, Gall WE, Cowan WM, eds), pp 3-92. New York: Wiley.

Sarantis M, Ballerini L, Miller B, Silver RA, Edwards M, Attwell D (1993) Glutamate uptake from the synaptic cleft does not shape the decay of the non-NMDA component of the synaptic current. Neuron 11:541-549.

Schultz K, Stell WK (1996) Immunocytochemical localization of the high-affinity glutamate transporter, EAAC1, in the retina of representative vertebrate species. Neurosci Lett 211:191-194.

Slaughter MM, Miller RF (1983) An excitatory amino acid antagonist blocks cone input to sign-conserving second-order retinal neurons. Science 219:1230-1232.

Tachibana M, Okada T (1991) Release of endogenous excitatory amino acids from ON-type bipolar cells isolated from the goldfish retina. J Neurosci 11:2199-2208.

Taschenberger H, Engert F, Grantyn R (1995) Synaptic current kinetics 
in a solely AMPA-receptor-operated glutamatergic synapse formed by rat retinal ganglion neurons. J Neurophysiol 74:1123-1136.

Taylor WR, Chen E, Copenhagen DR (1995) Characterization of spontaneous excitatory synaptic currents in salamander retinal ganglion cells. J Physiol (Lond) 486:207-221.

Tong G, Jahr CE (1994) Block of glutamate transporters potentiates postsynaptic excitation. Neuron 13:1195-1203.

Trussell LO, Zhang S, Raman IM (1993) Desensitization of AMPA receptors upon multiquantal neurotransmitter release. Neuron 10:1185-1196.

Vandenbranden CAV, Verweij J, Kamermans M, Müller CJ, Ruijter JM, Vrensen GFJM, Spekreijse H (1996) Clearance of neurotransmitter from the cone synaptic cleft in goldfish retina. Vision Res 36:3859-3874.

von Gersdorff H, Matthews G (1994) Dynamics of synaptic vesicle fusion and membrane retrieval in synaptic terminals. Nature 367:735-739.

von Gersdorff H, Sakaba T, Berglund K, Tachibana M (1998) Submillisecond kinetics of glutamate release from a sensory synapse. Neuron 21:1177-1188.

Yamada KA, Tang C-M (1993) Benzothiadiazides inhibit rapid glutamate receptor desensitization and enhance glutamatergic synaptic currents. J Neurosci 13:3904-3915.

Yang J-H, Wu SM (1997) Characterization of glutamate transporter function in the tiger salamander retina. Vision Res 37:827-838. 